\title{
RUGOSIDADE DA SUPERFÍCIE DE UM CAMBISSOLO HÚMICO RELACIONADA COM O PREPARO E COMPACTAÇÃO DO SOLO SOB CHUVA NATURAL ${ }^{(1)}$
}

\author{
Ivana Manenti Capistrano Correa ${ }^{(2)}$, Ildegardis Bertol( ${ }^{(3)}$, Júlio César \\ $\operatorname{Ramos}^{(4)} \&$ Marcelo Masahiko Takizawa ${ }^{(4)}$
}

\begin{abstract}
RESUMO
A rugosidade superficial do solo é uma característica importante, pois influencia a infiltração e a armazenagem de água no solo, a retenção de sedimentos na superfície e a erosão hídrica. Por sua vez, a rugosidade é influenciada pelo preparo, umidade e compactação do solo, pelos resíduos culturais, pelo efeito residual do uso do solo e pela erosividade da chuva. Este trabalho teve o objetivo de quantificar o efeito do tipo de preparo, da compactação do solo e da erosividade da chuva sobre o índice de rugosidade superficial ao acaso modificado (RRM), em um experimento conduzido sob chuva natural em um Cambissolo Húmico Alumínico léptico, com declividade média de $0,03 \mathrm{~m} \mathrm{~m}^{-1}$, entre setembro e novembro de 2008, em Lages, SC, com os seguintes tratamentos: (1) superfície quase lisa em solo compactado (LIC); (2) superfície quase lisa em solo não compactado (LINC); (3) uma aração e duas gradagens em solo compactado (PCC); (4) uma aração e duas gradagens em solo não compactado (PCNC); (5) uma escarificação em solo compactado (ESC); e (6) uma escarificação em solo não compactado (ESNC). O microrrelevo do solo foi medido com rugosímetro mecânico de varetas, em seis oportunidades: imediatamente antes e imediatamente após instalar os tratamentos; e após a ocorrência de cada um dos valores de erosividade ( $\left.\mathrm{EI}_{30}\right)$ da chuva: $136,190,630$ e $265 \mathrm{MJ} \mathrm{mm} \mathrm{ha}^{-1} \mathrm{~h}^{-1}$. O preparo do solo com aração e gradagens e com escarificação aumentou o índice RRM em relação a antes do preparo, tanto em solo não compactado quanto em solo compactado. $O$ aumento desse índice foi de 3,72 vezes em aração e gradagens
\end{abstract}

(1) Parte da Dissertação de Mestrado do primeiro autor. Recebido para publicação em 3 de maio de 2011 e aprovado em 20 de janeiro de 2012.

(2) Mestranda do Curso de Pós-Graduação em Ciência do Solo do CAV, Universidade do Estado de Santa Catarina - UDESC. Caixa Postal 281, Av. Luis de Camões 2090, CEP 88520-000 Lages (SC). E-mail: a6imcc@cav.udesc.br

(3) Professor de Uso e Conservação do Solo do CAV/UDESC. Bolsista do CNPq. E-mail: a2ib@cav.udesc.br

(4) Aluno do Curso de Agronomia do CAV/UDESC. Bolsista de Iniciação Científica. E-mails: a6jcr@cav.udesc.br; a6mmt@cav.udesc.br 
e de 3,88 vezes na escarificação, na média do solo compactado e não compactado. A compactação do solo aumentou o índice RRM, independentemente do tipo de preparo. No caso da aração e gradagens, o aumento nesse índice foi de 4,58 vezes no solo compactado e de 3,04 vezes no não compactado, logo após o preparo; em se tratando da escarificação, em solo compactado o aumento pelo preparo foi de 5,49 vezes e de 2,61 vezes no solo não compactado, também logo após o preparo. A erosividade da chuva diminuiu o índice RRM, independentemente do tipo de preparo e da compactação do solo, cuja relação foi descrita pelo modelo $y=\mathrm{ae}^{-\mathrm{bx}}$.

Termos de indexação: microrrelevo superficial, rugosímetro, erosividade.

\section{SUMMARY: SURFACE ROUGHNESS OF AN ICEPTISOL RELATED WITH SOIL TILLAGE AND COMPACTION UNDER NATURAL RAIN- FALL}

Surface roughness is a relevant soil property in terms of its influence on soil water infiltration and storage, sediment retention on the soil surface, and water erosion. In turn, surface roughness is influenced by soil tillage, moisture, compaction, crop residues, residual effects of land use, and by rainfall erosivity. The purpose of this study was to quantify the effect of soil tillage type, soil compaction and rainfall erosivity on surface roughness. The experiment assessed an Inceptsol with a relatively flat slope $\left(0.03 \mathrm{~m} \mathrm{~m}^{-1}\right)$ under natural rainfall in Lages, Santa Catarina, Brazil, from September to November 2008, with the following treatments: 1) nearly smooth surface of compacted soil (SSC); 2) nearly smooth surface of uncompacted soil (SSNC); 3) tillage (plowing and two diskings) of compacted soil (SPC); 4) tillage (plowing and two diskings) of uncompacted soil (SPNC); 5) tillage (chiseling) of compacted soil (SCC); 6) tillage (chiseling) of uncompacted soil (SCNC). The micro-relief was determined with the contact styli of a rugosimeter six times: immediately before and immediately after treatment application; and after the occurrence of each of the following rainfall erosivity $\left(E I_{30}\right)$ values: 136; 190; 630; and $265 \mathrm{MJ} \mathrm{mm} \mathrm{ha}^{-1} \mathrm{~h}^{-1}$. After tillage with plowing and disking and with chiseling the modified random roughness index was higher than before, in compacted and uncompacted soil. The random roughness was on average 3.72 times higher after plowing and disking and 3.88 times higher after chiseling, in compacted and uncompacted soil. The surface roughness index increased in the compacted soil, independently of the soil till type. In the case of plowing and disking, the increase was 4.58 times in the compacted and 3.04 times in uncompacted soil, immediately after tilling, while in the case of chiseling, the roughness index increased 5.49 times in the compacted and 2.61 times in the uncompacted soil, also immediately after tilling. Rainfall erosivity decreased the soil surface random roughness, independently of soil tillage and compaction; the relation was described by the model $y=a e^{-b x}$.

Index terms: surface micro-relief, microrelief meter, erosivity.

\section{INTRODUÇÃO}

A rugosidade do solo é uma importante característica física de superfície na redução da erosão hídrica, pois ela aumenta a retenção e infiltração de água no solo, reduz a velocidade e volume de enxurrada e aumenta a deposição de sedimentos na superfície do solo (Magunda et al., 1997; Castro et al., 2006). Assim, apesar de efêmera, devido à ação da chuva, a rugosidade da superfície do solo induzida pelo preparo é importante inclusive nos sistemas de manejo conservacionistas.
A rugosidade superficial do solo é representada pela micro-ondulação do terreno, ou seja, pelas microdepressões e microelevações da superfície do solo distribuídas espacialmente, sendo expressa por um índice que depende de fatores intrínsecos do solo, de acordo com seus atributos e com o teor de água no momento do preparo (Allmaras et al., 1966; Eltz \& Norton, 1997; Vidal Vázquez et al., 2010), mas, principalmente, depende de fatores externos, como tipo, quantidade e forma de manejo do resíduo vegetal e tipo e intensidade do preparo mecânico (Cogo et al., 1984; Kamphorst et al., 2000; Bertol et 
al., 2006), além de depender também da compactação do solo (Zoldan Jr., 2006).

O preparo mecânico do solo é a principal forma de alteração da rugosidade superficial e, como consequência, altera alguns processos hidrológicos, algumas variáveis hidráulicas e a erosão do solo (Castro et al., 2006; Bertol et al., 2008; Panachuki et al., 2010). O solo preparado com uma escarificação e uma gradagem, como no cultivo mínimo, proporciona superfície mais rugosa do que quando preparado com uma aração e gradagens, como no preparo convencional (Panachuki et al., 2010). Por sua vez, a rugosidade superficial no preparo convencional é maior do que na semeadura direta (Cogo et al., 1984). A mobilização do solo realizada com equipamentos de preparo primário aumenta a rugosidade superficial em comparação aos equipamentos de preparo secundário (Cogo et al., 1984). Do mesmo modo, maior quantidade de resíduos vegetais e,ou, menor teor de água no solo resulta em maior rugosidade do que menor quantidade de resíduos e,ou, maior teor de água disponível, quando o solo é preparado (Cogo et al., 1984). Por outro lado, o solo compactado resulta em maior rugosidade do que o não compactado quando sob preparo (Zoldan Jr. et al., 2008). A energia cinética das gotas de chuva é um agente natural de compactação, pois, quando elas atingem o solo descoberto, desagregamno e promovem a acomodação das partículas, compactando-o, o que leva ao selamento superficial, que reduz drasticamente a infiltração de água no solo (McIntyre, 1958).

A maior parte da redução de rugosidade ao acaso acontece durante o período anterior ao início da enxurrada (Zoldan Jr. et al., 2008) em solo preparado com uma operação de aração, duas de gradagem e uma de nivelamento (com rastelo semelhante ao da gradagem de dentes), o que foi observado também por Cogo et al. (1984). Isso indica que a redução da rugosidade da superfície relaciona-se exponencialmente com o aumento da erosividade da chuva, como verificado por Zoldan Jr. et al. (2008).

Em geral, o aumento da rugosidade superficial do solo por efeito do preparo mecânico é maior do que a diminuição da mesma rugosidade por efeito da erosividade da chuva sobre solo recém-preparado (Castro et al., 2006; Bertol et al., 2007; Zoldan Jr. et al., 2008). Em solo sem revolvimento mecânico, no entanto, a ação da erosividade da chuva pouco diminui a rugosidade, em comparação à diminuição desta ocorrida em solo com revolvimento (Castro et al., 2006).

A partir do exposto, pode-se considerar a hipótese de que a rugosidade ao acaso da superfície do solo é influenciada pelo tipo de preparo mecânico e pelo grau de compactação do solo na camada superficial, bem como que essa rugosidade diminui com o aumento da erosividade da chuva, de maneira distinta em diferentes tipos de preparo mecânico e graus de compactação do solo.

O objetivo deste trabalho foi avaliar a rugosidade ao acaso modificada, ocasionada por três tipos de preparo mecânico do solo em condições de solo compactado (mantido sem preparo por três anos) e não compactado (recém-revolvido), bem como relacionar essa rugosidade com a erosividade das chuvas naturais.

\section{MATERIAL E MÉTODOS}

O experimento foi conduzido em campo, sob condições de chuva natural, entre os meses de setembro e novembro de 2008, no campus do Centro de Ciências Agroveterinárias de Lages (SC), localizado na região Sul do Planalto Catarinense (27 $49^{\prime}$ de latitude sul, $50^{\circ} 20^{\prime}$ de longitude oeste e $937 \mathrm{~m}$ de altitude). O clima é do tipo $\mathrm{Cfb}$, segundo a classificação de Köppen, correspondente a subtropical úmido, chuvoso, com verões frescos. O solo do local do experimento é um Cambissolo Húmico Alumínico léptico, argiloso, com horizonte A moderado (Embrapa, 2006), com algumas características e propriedades apresentadas no quadro 1.

A área experimental foi cultivada durante 15 anos antes da instalação do experimento, com uma sequência de ervilhaca, milho, aveia, soja, nabo forrageiro e feijão. Nos primeiros cinco anos os cultivos foram manejados com o preparo do solo com uma aração e duas gradagens, e, nos últimos 10 anos, os cultivos foram sem revolvimento do solo. Nos últimos três anos, entre março de 2005 e fevereiro de 2008, antes da instalação do experimento, a área toda foi mantida sem cultivo. Em início de março de 2008 foi efetuada uma capina manual com enxada em toda a área experimental. A mesma operação foi feita por mais três vezes, iniciando-se 30 dias após a recém-referida capina, espaçada de 45 dias uma da outra, totalizando 135 dias entre a primeira e a terceira capina, nos locais onde posteriormente foram instalados os tratamentos em solo compactado. Nesse momento, a densidade do solo era de $1,45 \mathrm{Mg} \mathrm{m}^{-3}$, na camada entre $3 \mathrm{e}$ $15 \mathrm{~cm}$. Nos locais onde mais tarde foram instalados os tratamentos em solo não compactado, foi efetuado o preparo do solo três vezes, nas mesmas datas em que se efetuaram as últimas três capinas recémreferidas. Em cada preparo, fez-se uma aração com arado de discos na profundidade de 18-20 cm e duas gradagens com grade leve de discos na profundidade de $10-12 \mathrm{~cm}$. Nesse momento, a densidade do solo era de $0,95 \mathrm{Mg} \mathrm{m}^{-3}$, na camada de 3 a $15 \mathrm{~cm}$. A área toda foi mantida sem cultivo e descoberta durante 
Quadro 1. Algumas características e propriedades do Cambissolo Húmico Alumínico léptico, referentes ao perfil do solo descrito no local do experimento (adaptado de Guadagnin, 2003)

\begin{tabular}{|c|c|c|c|c|c|c|}
\hline & \multicolumn{6}{|c|}{ Horizonte } \\
\hline & Ap & A2 & $\mathrm{B} / \mathrm{A}$ & B & $\mathrm{B} / \mathrm{C}$ & $\mathbf{C}$ \\
\hline & \multicolumn{6}{|c|}{ Camada (cm) } \\
\hline & $0-20$ & $20-34$ & $34-53$ & $53-75 / 82$ & $75 / 82-105$ & $105+$ \\
\hline & \multicolumn{6}{|c|}{ Característica/Propriedade } \\
\hline Argila (g $\left.100 \mathrm{~g}^{-1}\right)$ & 40 & 40 & 42 & 46 & 52 & 32 \\
\hline Silte $\left(\mathrm{g} 100 \mathrm{~g}^{-1}\right)$ & 42 & 40 & 41 & 40 & 35 & 65 \\
\hline Areia fina (g $\left.100 \mathrm{~g}^{-1}\right)$ & 11 & 10 & 10 & 9 & 8 & 2 \\
\hline Areia grossa $\left(\mathrm{g} 100 \mathrm{~g}^{-1}\right)$ & 7 & 10 & 7 & 5 & 5 & 1 \\
\hline Dens. Part. $\left(\mathrm{g} \mathrm{cm}^{-3}\right)$ & 2,54 & 2,56 & 2,61 & 2,61 & 2,70 & 2,38 \\
\hline C. orgânico $\left(\mathrm{g} \mathrm{kg}^{-1}\right)$ & 40 & 20 & 20 & 10 & 10 & - \\
\hline $\mathrm{N}$ mineral (mg kg-1) & 5,0 & 0,1 & 0,1 & 0,1 & 0,1 & 0,0 \\
\hline $\mathrm{P}$ disponível ( $\left.\mathrm{mg} \mathrm{kg}^{-1}\right)$ & 2,6 & 3,1 & 0,6 & 0,4 & 0,7 & 0,3 \\
\hline $\mathrm{K}$ disponível (mg kg-1) & 96 & 80 & 49 & 61 & 42 & 57 \\
\hline Ca troc. $\left(\mathrm{cmol}_{\mathrm{c}} \mathrm{kg}^{-1}\right)$ & 2,63 & 3,05 & 0,68 & 0,45 & 0,72 & 0,29 \\
\hline Mg troc. $\left(\mathrm{cmol}_{\mathrm{c}} \mathrm{kg}^{-1}\right)$ & 2,17 & 2,33 & 0,78 & 0,68 & 0,70 & 0,31 \\
\hline $\mathrm{Al}$ troc. $\left(\mathrm{cmol}_{\mathrm{c}} \mathrm{kg}^{-1}\right)$ & 2,27 & 3,47 & 5,89 & 6,52 & 3,96 & 4,68 \\
\hline
\end{tabular}

esse período e também posteriormente, durante a fase experimental, sendo as plantas daninhas controladas manualmente.

Os cinco tratamentos, em duas repetições, totalizando 10 parcelas com $1 \mathrm{~m}^{2}$ cada uma ( $\left.1 \mathrm{x} 1 \mathrm{~m}\right)$, distribuídas ao acaso, foram instalados em início de setembro de 2008, ou seja, 15 dias após as últimas operações de capina manual e de preparo do solo com aração e gradagens recém-referidas: T1) superfície quase lisa em solo compactado, no qual não se efetuou preparo algum, apenas um alisamento com enxada, pouco antes de se instalar o tratamento sobre a parcela que havia sido somente capinada (LIC); T2) superfície quase lisa em solo não compactado, no qual se efetuou uma aração a $18-20 \mathrm{~cm}$ de profundidade e duas gradagens a $10-12 \mathrm{~cm}$ e se destorroou e alisou a superfície do solo manualmente com rastelo, pouco antes de se instalar o tratamento sobre a parcela que havia sido preparada com aração e gradagens (LINC); T3) superfície rugosa em solo compactado, no qual se efetuou o preparo do solo com uma aração e duas gradagens, pouco antes de se instalar o tratamento sobre a parcela que havia sido somente capinada (PCC); T4) superfície rugosa em solo não compactado, no qual se efetuou preparo do solo com uma aração e duas gradagens, pouco antes de se instalar o tratamento sobre a parcela que havia sido preparada com aração e gradagens (PCNC); T5) superfície rugosa em solo compactado, no qual se efetuou o preparo do solo com uma escarificação a $15 \mathrm{~cm}$ de profundidade, pouco antes de se instalar o tratamento sobre a parcela que havia sido somente capinada (ESC); e T6) superfície rugosa em solo não compactado, no qual se efetuou o preparo do solo com uma escarificação, pouco antes de se instalar o tratamento sobre a parcela que havia sido preparada com aração e gradagens (ESNC). A distância entre as hastes do escarificador era de $20 \mathrm{~cm}$.

A rugosidade superficial do solo foi avaliada numa área de $0,36 \mathrm{~m}^{2}(0,6 \times 0,6 \mathrm{~m})$ no centro de cada parcela, com o rugosímetro mecânico de varetas (Figura 1), para obtenção das alturas do microrrelevo do solo, em seis momentos: imediatamente antes e imediatamente após o preparo do solo nos tratamentos com preparo e nos mesmos momentos, também nos tratamentos sem preparo; 13 dias depois da segunda avaliação, após a ocorrência de $78 \mathrm{~mm}$ de chuva $\left(\mathrm{EI}_{30}=136 \mathrm{MJ} \mathrm{mm} \mathrm{ha}^{-1} \mathrm{~h}^{-1}\right) ; 22$ dias depois da terceira avaliação, após a ocorrência de $82 \mathrm{~mm}$ de chuva $\left(\mathrm{EI}_{30}=190 \mathrm{MJ} \mathrm{mm} \mathrm{ha}^{-1} \mathrm{~h}^{-1}\right) ; 22$ dias depois da quarta avaliação, após a ocorrência de $230 \mathrm{~mm}$ de chuva $\left(\mathrm{EI}_{30}=630 \mathrm{MJ} \mathrm{mm} \mathrm{ha}^{-1} \mathrm{~h}^{-1}\right)$; e 28 dias depois da quinta avaliação, após a ocorrência de $122 \mathrm{~mm}$ de chuva $\left(\mathrm{EI}_{30}=265 \mathrm{MJ} \mathrm{mm} \mathrm{ha}^{-1} \mathrm{~h}^{-1}\right)$. Portanto, ao longo do período de avaliação da rugosidade, após a instalação dos tratamentos, ocorreu um volume de chuva acumulado de $512 \mathrm{~mm}$, equivalente a $\mathrm{EI}_{30}=$ 1.221 $\mathrm{MJ} \mathrm{mm} \mathrm{ha-1}^{-1}$ (Quadro 2).

As chuvas foram registradas em pluviogramas diários com amplitude de registro de $10 \mathrm{~mm}$ de precipitação e de $24 \mathrm{~h}$ de duração, com unidades de 0,1 mm para o volume e de 10 min para o tempo. Após as chuvas terem sido cotadas manualmente em segmentos de intensidade uniforme, a energia 
Quadro 2. Número, volume e erosividade das chuvas ocorridas na área experimental onde se efetuou o estudo

\begin{tabular}{|c|c|c|c|c|}
\hline Período & $\begin{array}{l}\text { Chuvas } \\
\text { erosivas }\end{array}$ & $\begin{array}{l}\text { Volume de chuva por } \\
\text { intervalo de tempo }\end{array}$ & $\begin{array}{l}\text { Volume de chuva } \\
\text { acumulado }\end{array}$ & $\begin{array}{l}\text { Erosividade }\left(\mathrm{EI}_{30}\right) \text { das } \\
\text { chuvas por intervalo }\end{array}$ \\
\hline & $\mathrm{n}^{0}$ & $\longrightarrow \mathrm{mm}$ & 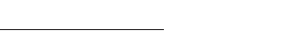 & MJ mm ha- $\mathrm{h}^{-1}$ \\
\hline 06/09/08 a $15 / 09 / 08$ & 3 & 78 & 78 & 136 \\
\hline $16 / 09 / 08$ a $07 / 10 / 08$ & 1 & 82 & 160 & 190 \\
\hline 08/10/08 a $30 / 10 / 08$ & 8 & 230 & 390 & 630 \\
\hline $31 / 10 / 08$ a $26 / 11 / 08$ & 5 & 122 & 512 & 265 \\
\hline Total & 19 & 512 & 512 & 1.221 \\
\hline
\end{tabular}

cinética unitária foi calculada pela equação proposta por Wischmeier \& Smith (1958): Ec = 0,119 + 0,0873 $\log _{10}$ I, em que: $\mathrm{Ec}=$ energia cinética por $\mathrm{mm}$ de chuva, MJ ha ${ }^{-1} \mathrm{~mm}^{-1} ; \mathrm{e} \mathrm{I}=$ intensidade da chuva, $\mathrm{mm}$ $\mathrm{h}^{-1}$. A erosividade foi expressa como sendo o $\mathrm{EI}_{30}$, em que: $\mathrm{E}=$ energia cinética total da chuva, $\mathrm{MJ} \mathrm{ha}^{-1}$; $\mathrm{e}$ $\mathrm{I}_{30}=$ intensidade máxima em 30 min de chuva, $\mathrm{mm}$ $\mathrm{h}^{-1}$, conforme Wischmeier \& Smith (1978). Na equação, as unidades inglesas são convertidas para o Sistema Internacional de Unidades, conforme sugerido por Foster et al. (1981).

O rugosímetro de varetas (Figura 1) consiste de uma estrutura sobre a qual é apoiado um conjunto de varetas alinhadas que podem ser movimentadas

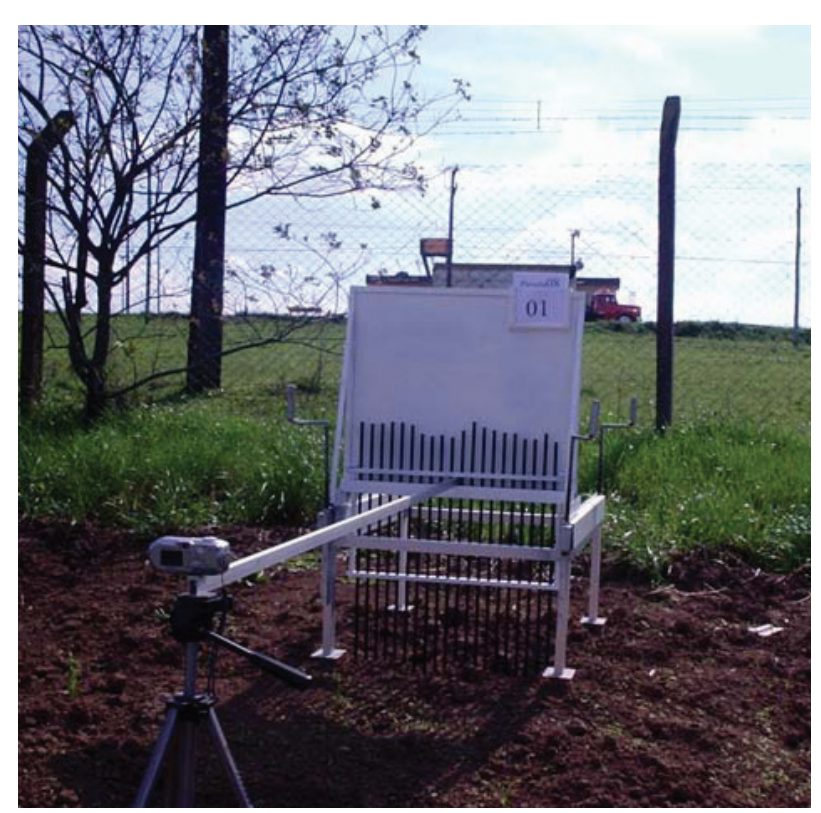

Figura 1. Rugosímetro de varetas utilizado no estudo, sendo operado no experimento sobre um Cambissolo Húmico Alumínico léptico. Lages, SC. horizontal e verticalmente, com o objetivo de permitir a leitura de vários conjuntos de medidas do microrrelevo superficial. O rugosímetro contém 20 varetas de alumínio, com $600 \mathrm{~mm}$ de comprimento e $8 \mathrm{~mm}$ de diâmetro cada uma, distanciadas $30 \mathrm{~mm}$ uma das outras e distribuídas ao longo de um suporte do rugosímetro. No centro desse suporte, outra barra com $1,80 \mathrm{~m}$ de comprimento está fixada perpendicularmente, e em cuja extremidade livre se localiza uma câmera fotográfica, com a qual é obtida a fotografia do conjunto de varetas, registrando a rugosidade do solo. Isso possibilitou a tomada de uma fotografia do conjunto de varetas localizadas transversalmente ao declive da parcela e que refletia as alturas da superfície do solo. Movendo o conjunto de varetas sobre o suporte do rugosímetro, em espaço de $30 \mathrm{~mm}$ uma das outras, em 20 posições na direção da pendente da parcela, tomaram-se 20 fotografias em cada parcela, totalizando 400 pontos de altura da superfície do solo em cada parcela, conforme procedimento utilizado por Zoldan Jr. (2006). Portanto, a posterior digitalização das fotografias permitiu a leitura de 400 pontos de altura do microrrelevo superficial do solo na área de amostragem da parcela.

Obtidas as fotografias (Figura 2), elas foram tratadas mediante análise proposta por Lado Liñares \& Taboada Castro (1988). Os valores de altura do microrrelevo dos diferentes pontos foram obtidos mediante o uso do programa "Profile Meter Program", proposto por Wagner \& Yiming (1991) e Wagner (1992). Esse programa foi desenvolvido para obtenção de dados de análise de imagens que detectam as alturas das varetas em fotografias com formato digital, reduzindo, dessa forma, o erro do operador no processo de digitalização manual.

$\mathrm{Na}$ obtenção dos valores de altura do microrrelevo dos pontos amostrados, as 20 fotografias pertencentes a uma mesma série de medidas de cada parcela foram unidas, criando uma superfície ortogonal 

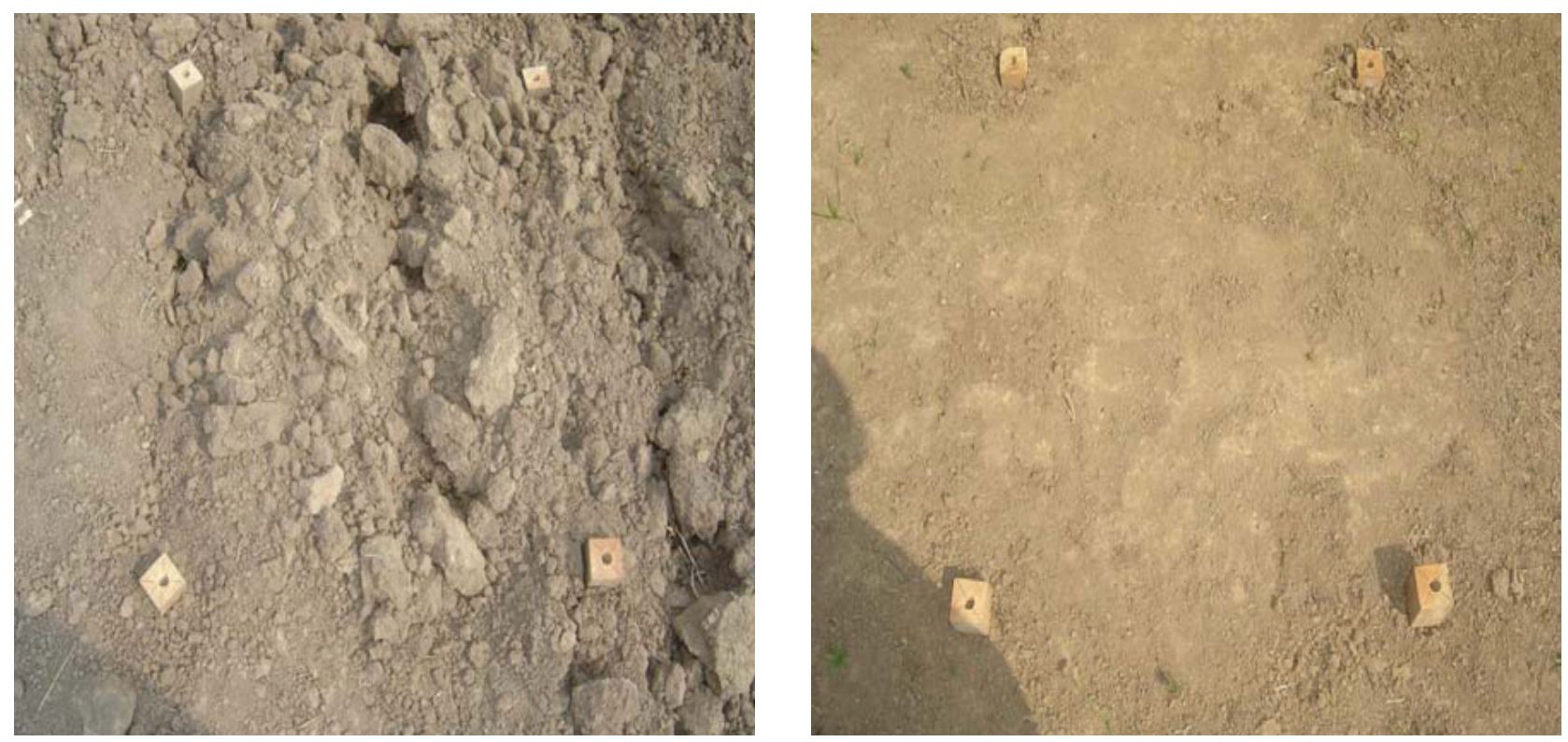

Figura 2. Superfície do solo referente aos tratamentos: uma aração e duas gradagens em solo não compactado (esquerda) e superfície quase lisa em solo compactado (direita).

de 400 pontos. Para cada ponto, obteve-se uma coordenada $(\mathrm{X}, \mathrm{Y})$ em função da distância, em ambos os eixos. Estimadas as cotas individuais de cada superfície, armazenaram-se esses dados em arquivo e, a partir deles, obtiveram-se os índices de rugosidade.

Com o uso de um programa computacional desenvolvido para a aquisição de dados de rugosidade com a utilização de técnicas de análise de imagens digitalizadas, proposto por Miranda (2000), estimouse o índice de rugosidade ao acaso modificado, para determinação da rugosidade ao acaso da superfície do solo. O índice de rugosidade foi calculado como sendo o desvio-padrão das 400 leituras das alturas das varetas que representavam o microrrelevo, sem transformação logarítmica e sem eliminar os $10 \%$ dos valores extremos, conforme modificação proposta por Kamphorst et al. (2000) no índice originalmente proposto por Allmaras et al. (1966).

O índice de rugosidade ao acaso modificado foi calculado sem a influência da declividade do terreno e da tendência das marcas do preparo do solo. A casualidade na distribuição das microdepressões e microelevações do terreno é uma característica da rugosidade superficial do solo. Assim, é necessário eliminar as componentes de orientação, devidas à declividade do terreno e às tendências das marcas de preparo do solo. Para remover a tendência devida à declividade do terreno, efetuou-se um ajuste da superfície linear por mínimos quadrados dos valores originais, de acordo com método proposto por Miranda (2000). Para retirar ao mesmo tempo as componentes relacionadas à tendência da declividade do terreno e das marcas de preparo do solo, efetuaram-se correções dos dados na linha e na coluna de cada conjunto de 400 pontos, conforme método proposto por Currence \& Lovely (1970).

Para avaliar o efeito dos tratamentos e obter uma estimativa da variância residual, foi feita a análise de variância dos dados, com a posterior aplicação do teste de Tukey a $5 \%$, para a comparação de médias, utilizando-se o programa computacional ASSISTAT. Com o objetivo de observar a relação entre o índice de rugosidade e a erosividade das chuvas, ajustou-se entre as variáveis o modelo de regressão exponencial do tipo $\mathrm{y}=\mathrm{ae}^{-\mathrm{bx}}$, em que: $\mathrm{y}=$ índice de rugosidade ao acaso modificado, $\mathrm{mm} ; \mathrm{a}, \mathrm{b}=$ coeficientes de regressão não linear; e $\mathrm{x}=$ erosividade $\left(\mathrm{EI}_{30}\right)$ de chuva, MJ mm ha-1 $\mathrm{h}^{-1}$, utilizando-se o programa Sigma-Plot, versão 11.0.

\section{RESULTADOS E DISCUSSÃO}

\section{Efeito do tipo de preparo e da compactação do solo no índice de rugosidade superficial ao acaso modificado}

Na condição compactada, o índice de rugosidade superficial ao acaso modificado (RRM) foi maior quando o solo foi preparado com escarificação (ESC) do que com aração e duas gradagens (PCC) e, neste tratamento, maior do que no tratamento com a superfície do solo lisa (LIC); já no solo não compactado o índice RRM foi igual entre os tratamentos ESNC e PCNC e, nestes, maior do que no LINC (Quadro 3). O preparo com ESC e PCC 
Quadro 3. Efeito do tipo de preparo e compactação do solo de um Cambissolo Húmico Alumínico léptico, quanto ao índice de rugosidade superficial ao acaso modificado (média das repetições e das avaliações após o preparo e após as chuvas)

\begin{tabular}{llc}
\hline \multirow{1}{*}{ Tratamento } & \multicolumn{2}{c}{ Condição de compactação } \\
\cline { 2 - 3 } & Compactado & Não compactado \\
\cline { 2 - 3 } & & $\mathrm{mm}$ \\
Superfície quase lisa & $\mathrm{LIC}=1,87 \mathrm{cA}$ & $\mathrm{LINC}=2,45 \mathrm{bA}$ \\
Aração e gradagens & $\mathrm{PCC}=8,96 \mathrm{bA}$ & $\mathrm{PCNC}=7,16 \mathrm{aB}$ \\
Escarificação & $\mathrm{ESC}=9,84 \mathrm{aA}$ & $\mathrm{ESNC}=6,67 \mathrm{aB}$ \\
\hline
\end{tabular}

LIC: superfície quase lisa compactada; LINC: superfície quase lisa não compactada; PCC: aração e gradagens compactado; PCNC: aração e gradagens não compactado; ESC: escarificação compactado; ESNC: escarificação não compactado. DMS para colunas $=0,83$, letras minúsculas. DMS para linhas $=0,69$, letras maiúsculas.

em solo compactado ocasionou maior RRM do que no solo não compactado, enquanto, no tratamento LIC, a compactação não teve efeito algum sobre essa rugosidade. Isso demonstra que a intensidade de revolvimento influencia o índice RRM no solo compactado, conforme verificado também por Bertol et al. (2008). Nessa condição, essa rugosidade no tratamento ESC foi $10 \%$ maior do que no tratamento PCC. Assim, a menor intensidade de revolvimento ocorrido na escarificação propiciou maior índice RRM do que na aração e gradagens, em que a intensidade de preparo foi maior. No solo não compactado, por outro lado, a intensidade de preparo do solo não influenciou esse índice de rugosidade superficial, comparando os tratamentos ESNC e PCNC. Assim, os dados do quadro 3 mostram que o preparo mecânico realizado em solo compactado aumenta o índice RRM em relação à condição de solo não compactado. Esse efeito foi de $48 \%$ no tratamento com ESC e de $25 \%$ no tratamento PCC.

\section{Índice de rugosidade superficial ao acaso modificado, em função do tipo de preparo e da compactação do solo}

Os preparos do solo efetuados com escarificação e com aração e gradagens por ocasião da instalação dos tratamentos aumentaram o índice RRM, em comparação à ausência de preparo (Quadro 4), tanto no solo compactado quanto no não compactado, como verificado também por Vidal Vázquez (2002) e Zoldan Jr. et al. (2008). No caso da escarificação, o valor aumentou de $3,01 \mathrm{~mm}$ para $11,84 \mathrm{~mm}$, na média do solo compactado (ESC) e não compactado
(ESNC), respectivamente, enquanto, no caso da aração e gradagens, o valor do índice RRM passou de $3,01 \mathrm{~mm}$ para $11,37 \mathrm{~mm}$, também na média do solo compactado (PCC) e não compactado (PCNC). Dados semelhantes a esses foram obtidos também por Zoldan Jr et al. (2008).

Os dados do quadro 4 confirmam a maior eficácia da escarificação no aumento do índice de rugosidade superficial ao acaso modificado quando efetuada isoladamente, em comparação à combinação de aração e gradagens, também verificado por Cogo et al. (1984). No tratamento ESC (solo compactado), o aumento no índice RRM ocasionado pelo preparo foi de 5,5 vezes, e no ESNC (solo não compactado), de 2,6 vezes. Já no tratamento PCC (solo compactado), o aumento no índice de rugosidade foi de 4,6 vezes, enquanto no PCNC (solo não compactado) o referido aumento foi de 3,0 vezes (Quadro 4). O uso desses implementos agrícolas favoreceu a criação de torrões grandes (variando de 15 a $20 \mathrm{~cm}$ de diâmetro) por ocasião do preparo mecânico do solo. No entanto, houve tendência de a escarificação maximizar esse favorecimento, comparada à aração combinada com gradagens, verificado também por Cogo et al. (1984) e Vidal Vázquez (2002). Portanto, o cultivo mínimo efetuado com uma escarificação, além de mais econômico, é conservacionista em relação ao preparo com aração e gradagens, pois minimiza os impactos negativos do preparo mecânico sobre o solo. Isso é importante salientar, pois as operações de preparo do solo devem contemplar as necessidades das plantas, como o aumento de porosidade interna do solo, e as demandas conservacionistas do solo e da água, como o aumento da rugosidade superficial, de maneira harmônica.

Quadro 4. Índice de rugosidade superficial ao acaso modificado, antes e após o preparo de um Cambissolo Húmico Alumínico léptico (média de duas repetições)

\begin{tabular}{lcc}
\hline Tratamento & Antes & Após \\
\cline { 2 - 3 } & \multicolumn{2}{c}{$\mathrm{mm}$} \\
LIC & 2,68 & $2,68^{\mathrm{ns}}$ \\
LINC & 3,43 & $3,43^{\mathrm{ns}}$ \\
PCC & 2,69 & $12,32^{* *}$ \\
PCNC & 3,42 & $10,41^{* *}$ \\
ESC & 2,68 & $14,72^{* *}$ \\
ESNC & 3,43 & $8,96^{* *}$ \\
\hline
\end{tabular}

LIC: superfície quase lisa compactada; LINC: superfície quase lisa não compactada. PCC: aração e gradagens compactado; PCNC: aração e gradagens não consolidado; ESC: escarificação compactado; ESNC: escarificação não compactado; Efeito na linha, comparando antes e após o preparo do solo: ${ }^{* *}$ Significativo

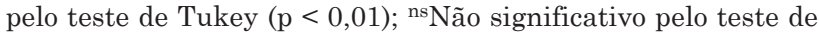
Tukey $(\mathrm{p}<0,05)$. 
Índice de rugosidade superficial ao acaso modificado, após o preparo do solo e após as chuvas

Os valores do índice RRM diminuíram a partir dos valores obtidos imediatamente após o preparo do solo (APP) em razão do efeito da erosividade das chuvas, independentemente do tipo de preparo e da compactação do solo (Quadro 5). A diminuição do índice RRM foi de $45 \%$ na superfície quase lisa, passando de $3,01 \mathrm{~mm}$ para $1,68 \mathrm{~mm}$. Na aração e gradagens, essa diminuição foi de $51 \%$, passando de $11,37 \mathrm{~mm}$ para $5,59 \mathrm{~mm}$, e na escarificação, de $54 \%$, passando de $11,84 \mathrm{~mm}$ para $5,48 \mathrm{~mm}-\mathrm{em}$ ambos os casos, considerando a média dos solos compactado e não compactado. A diminuição do índice RRM pelo efeito dos 1.221 MJ mm ha-1 $\mathrm{h}^{-1}$ de $\mathrm{EI}_{30}$ foi alta nos tratamentos em que o solo foi preparado com escarificação e com aração e gradagens, considerando-se que essa erosividade equivale a aproximadamente um quarto do total anual que normalmente ocorre na região, segundo Bertol et al. (2002). Maior efeito das chuvas iniciais do que das finais sobre o índice de rugosidade ao acaso também foi verificado por Panachuki et al. (2010).

Considerando os tratamentos PCC, PCNC, ESC e ESNC (Quadro 5), o índice de rugosidade RRM diminuiu em 20, 23, 21 e $15 \%$, respectivamente, entre os valores obtidos imediatamente após o preparo e aqueles obtidos após a ocorrência de $136 \mathrm{MJ} \mathrm{mm} \mathrm{ha}^{-1} \mathrm{~h}^{-1}$ de $\mathrm{EI}_{30}$. Entre a ocorrência dos valores de 136 e de $1.085 \mathrm{MJ} \mathrm{mm} \mathrm{ha}^{-1} \mathrm{~h}^{-1}$ de $\mathrm{EI}_{30}$ restantes, a diminuição desse índice de rugosidade, nos respectivos tratamentos, foi de $33,42,46$ e $39 \%$. Isso revela que o maior declínio da rugosidade superficial ocasionada pelo preparo do solo é observado por ocasião de ocorrência de valores iniciais de erosividade em comparação com valores posteriores, como constatado por Bertol et al. (2006), Bertol et al. (2007), Zoldan Jr. et al. (2008) e Panachuki et al. (2010).
Relações do índice de rugosidade superficial ao acaso modificado com a erosividade da chuva

As curvas na figura 3 demonstram que a ação da erosividade das chuvas diminuiu significativamente os valores de índice RRM, com maior magnitude nos tratamentos PCC, PCNC, ESC e ESNC do que em LIC e LINC. O modelo exponencial ajustouse bem aos valores de índice RRM influenciados pela erosividade das chuvas, mostrando, em geral, coeficientes de determinação altos, assim como ocorreu em estudos de Eltz \& Norton (1997), Bertol et al. (2006), Zoldan Jr. et al. (2008) e Panachuki et al (2010), com exceção do tratamento PCC (Figura 3a), no qual o ajuste do modelo aos dados foi baixo.

A ocorrência do valor de $136 \mathrm{MJ} \mathrm{mm} \mathrm{ha}^{-1} \mathrm{~h}^{-1} \mathrm{de}$ erosividade de chuva, distribuídos em três eventos, antecedendo a primeira avaliação da rugosidade superficial ao acaso modificado (RRM) (Quadro 2), ocasionou expressiva diminuição nos valores do índice RRM, em comparação com os valores obtidos imediatamente após o preparo, independentemente do tipo de preparo do solo e da compactação. Essa diminuição foi expressiva também em comparação com a diminuição do índice RRM ocorrida em função dos valores posteriores de erosividade. Esse comportamento confirma que o índice de rugosidade superficial ao acaso modificado é mais fortemente diminuído pelo efeito das erosividades iniciais do que finais, também constatado por Cogo et al. (1984), Eltz \& Norton (1997), Bertol et al. (2006) e Panachuki et al. (2010).

Ao incidir a chuva sobre a crista das microelevações, as partículas de solo que delas se desprenderam foram depositadas nas microdepressões. Assim, as microelevações foram rebaixadas e as microdepressões assoreadas mais intensamente nas erosividades iniciais; por isso, nesse momento houve maior diminuição do índice RRM do que nos momentos posteriores. Nas

Quadro 5. Índice de rugosidade superficial ao acaso modificado, após o preparo do solo (APP) e após a ocorrência das chuvas, em um Cambissolo Húmico Alumínico léptico (média de duas repetições)

\begin{tabular}{|c|c|c|c|c|c|c|}
\hline \multirow{2}{*}{ Momento da determinação } & \multicolumn{6}{|c|}{ Tratamento } \\
\hline & LIC & LINC & PCC & PCNC & ESC & ESNC \\
\hline APP & 2,68 & 3,43 & 12,32 & 10,41 & 14,72 & 8,96 \\
\hline Após $78 \mathrm{~mm}$ & 2,01 & 2,85 & 9,83 & 7,97 & 11,57 & 7,64 \\
\hline Após $160 \mathrm{~mm}$ & 1,61 & 2,48 & 9,43 & 7,55 & 10,04 & 7,18 \\
\hline Após $390 \mathrm{~mm}$ & 1,46 & 1,64 & 8,65 & 5,27 & 6,81 & 4,90 \\
\hline Após $512 \mathrm{~mm}$ & 1,59 & 1,77 & 6,55 & 4,63 & 6,30 & 4,66 \\
\hline
\end{tabular}

LIC: superfície quase lisa compactada; LINC: superfície quase lisa não compactada. PCC: aração e gradagens compactado; PCNC: aração e gradagens não compactado; ESC: escarificação compactado; ESNC: escarificação não compactado. 
(a)

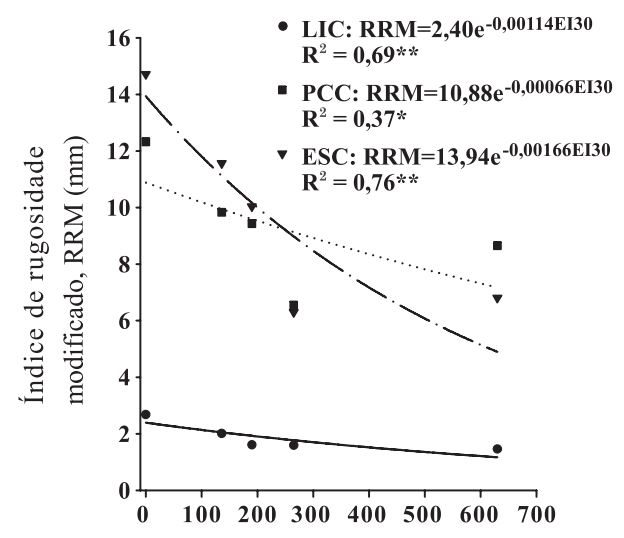

(b)

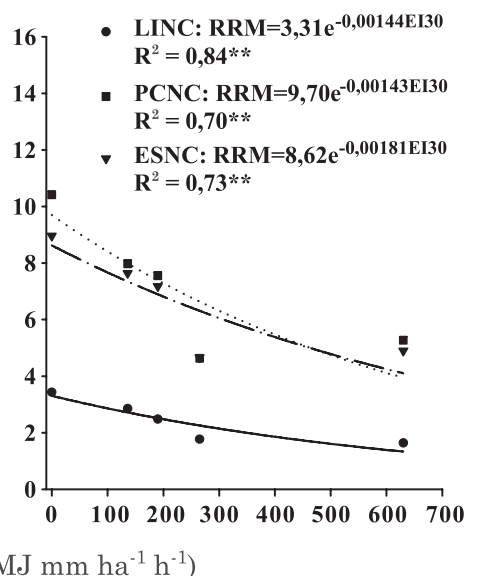

Figura 3. Relação entre o índice de rugosidade superficial ao acaso modificado (RRM) e a erosividade da chuva $\left(\mathrm{EI}_{30}\right)$, nos tratamentos superfície quase lisa em solo compactado (LIC) e não compactado (LINC), aração e gradagens em solo compactado (PCC) e não compactado (PCNC) e escarificação em solo compactado (ESC) e não compactado (ESNC), sobre um Cambissolo Húmico Alumínico léptico.

avaliações seguintes, percebe-se que o decaimento do índice RRM, embora acentuado, foi menos expressivo do que na primeira avaliação (Figura 3). Isso ocorreu porque a superfície do solo encontravase mais adensada por ocasião das avaliações finais, devido à ação da erosividade das chuvas, do que por ocasião da primeira avaliação, quando as chuvas ainda não haviam precipitado. Nos tratamentos PCC, PCNC, ESC e ESNC, o coeficiente de decaimento da rugosidade superficial do solo foi expressivamente maior do que no LIC e LINC. Isso está relacionado, em parte, com a alta rugosidade produzida pelos implementos agrícolas usados nos primeiros tratamentos citados e, no caso do tratamento LIC, também com a compactação do solo. O modelo $y=a e^{-b x}$ ajustou-se aos dados com significância estatística. No solo compactado (Figura 3a), os coeficientes de determinação foram de $0,70,0,38$ e 0,76 , para a condição de superfície lisa, preparo do solo com aração e gradagens e com escarificação, respectivamente. No solo não compactado (Figura 3b), esses coeficientes dos referidos tratamentos foram de $0,94,0,70$ e 0,73 , respectivamente.

\section{CONCLUSÕES}

1. O preparo do solo com aração e gradagens e com escarificação aumentou o índice de rugosidade superficial ao acaso modificado em relação a antes do preparo, tanto em solo não compactado quanto em solo compactado. $\mathrm{O}$ aumento desse índice de rugosidade foi de 3,72 vezes na aração e gradagens e de 3,88 vezes na escarificação, na média dos solos compactado e não compactado.
2. A compactação do solo aumentou o índice de rugosidade superficial ao acaso modificado, independentemente do tipo de preparo. No caso da aração e gradagens, o aumento desse índice foi de 4,58 vezes no solo compactado e de 3,04 vezes no não compactado, imediatamente após o preparo; já em se tratando da escarificação, em solo compactado o aumento desse índice pelo preparo foi de 5,49 vezes, sendo de 2,61 vezes no solo não compactado.

3. A erosividade da chuva diminuiu o índice de rugosidade superficial ao acaso modificado, independentemente do tipo de preparo e da compactação do solo, o qual decresceu com o aumento da erosividade, cuja relação foi descrita pelo modelo $y=a e^{-b x}$.

\section{LITERATURA CITADA}

ALLMARAS, R.R.; BURWELL, R.E.; LARSON, W.E. \& HOLT, R.F. Total porosity and roughness of the interrow zone as influenced by tillage. Washington, USDA, 1966. 22p. (Cons. Res. Report, 7)

BERTOL, I.; SCHICK, J.; BATISTELA, O.; LEITE, D.; VISENTIN, D. \& COGO, N.P. Erosividade das chuvas e sua distribuição entre 1989 e 1998 no município de Lages (SC). R. Bras. Ci. Solo, 26:455-464, 2002.

BERTOL, I.; AMARAL, A.J.; VIDAL VÁZQUEZ, E.; PAZ GONZÁLEZ, A.; BARBOSA, F.T. \& BRIGNONI, L.F. Relações da rugosidade superficial do solo com o volume de chuva e com a estabilidade de agregados em água. R. Bras. Ci. Solo, 30:543-553, 2006.

BERTOL, I.; PAZ GONZÁLES, A. \& VIDAL VÁZQUEZ, E. Rugosidade superficial do solo sob diferentes doses de resíduo de milho submetido à chuva simulada. Pesq. Agropec. Bras., 42:103-110, 2007. 
BERTOL, I.; ZOLDAN JR, W.A.; FABIAN, E.L.; ZAVASCHI, E.; PEGORARO, R. \& PAZ GONZÁlEZ, A. Efeito de escarificação e da erosividade de chuvas sobre algumas variáveis de valores de erosão hídrica em sistemas de manejo de um Nitossolo Háplico. R. Bras. Ci. Solo, 32:747$757,2008$.

CASTRO, L.G.; COGO, N.P. \& VOLK, L.B.S. Alterações na rugosidade superficial do solo pelo preparo e pela chuva e sua relação com a erosão hídrica. R. Bras. Ci. Solo, 30:339$352,2006$.

COGO, N.P.; MOLDENHAUER, W.C. \& FOSTER, G.R. Soil loss reductions from conservation tillage practices. Soil Sci. Soc. Am. J., 48:368-373, 1984.

CURRENCE, H.D. \& LOVELY, W.G. The analysis of soil surface roughness. Trans. Am. Soc. Agric. Eng., 13:710-714, 1970.

EMPRESA BRASILEIRA DE PESQUISA AGROPECUÁRIA EMBRAPA. Centro Nacional de Pesquisa de Solos. Sistema brasileiro de classificação de solos. 2.ed. Rio de Janeiro, 2006. 399p.

ELTZ, F.L.F. \& NORTON, L.D. Surface roughness changes as affected by rainfall erosivity, tillage, and canopy cover. Soil Sci. Soc. Am. J., 61:1746-1755, 1997.

FOSTER, G.R.; McCOOL, D.K.; RENARD, K.E. \& MOLDENHAUER, W.C. Conversion of the universal soil loss equation to SI metric units. Soil Water Conserv., 36:355-359, 1981.

GUADAGNIN, J.C. Perdas de nutrientes e carbono orgânico pela erosão hídrica, em um Cambissolo Húmico Alumínico léptico submetido a diferentes sistemas de preparo e cultivo do solo. Lages, Universidade do Estado de Santa Catarina, 2003, 150p. (Dissertação de Mestrado)

KAMPHORST, E.C.; JETTEN, V.; GUÉRIF, J.; PITKANEN, J.; IVERSEN, N.V.; DOUGLAS J.T. \& GONZÁLES, A.P. Predicting depressional storage from soil surface roughness. Soil Sci. Soc. Am. J., 64:1749-1758, 2000.

LADO LIÑARES, M. \& TABOADA CASTRO, M.M. Medida de la rugosidad del suelo en terrenos de cultivo. In: GÓMEZ ORTIZ, A. \& SALAVADOR FRANCH, F., eds. REUNIÓN NACIONAL DE GEOMORFOLOGÍA, 5., Barcelona, 1988. Proceedings... Barcelona, 1988. p.731-734.

MAGUNDA, M.K.; LARSON, W.E.; LINDEN, D.R. \& NATER, E.A. Changes in microrelieff and their effects on infiltration amd erosion during simulated rainfall. Soil Technol., 10:5767, 1997.
McINTYRE, D.S. Permeability measurements of soil crusts formed by raindrops impact. Soil Sci., 85:185-189, 1958.

MIRANDA, J.G.V. Análisis fractal del microrrelieve del suelo. A Coruña, Universidad da Coruña, 2000. 313p. (Tese de Doutorado)

PANACHUKI, E.; BERTOL, I.; ALVES SOBRINHO, T.; VITORINO, A.C.T.; SOUZA, C.M.A. \& URCHEI, MA. A rugosidade da superfície do solo sob diferentes sistemas de manejo e influenciada por chuva artificial. R. Bras. Ci. Solo, 34:443-451, 2010.

VIDAL VÁZQUEZ, E. Influencia de la precipitación y el laboreo en la rugosidad del suelo y la retención de agua en microdepresiones. A Coruña, Universidad da Coruña, 2002. 430p. (Tese de Doutorado)

VIDAL VÁZQUEZ, E.; BERTOL, I.; SIQUEIRA, G.M.; PAZFERREIRO, J. \& DAFONTE, J.D. Evolution of the soil surface roughness using geostatistical analysis. Bragantia, 69:141-152, 2010.

WAGNER, L.E. Profile meter program. Washington, Documentation. United States/Departament of Agriculture/ Agricultural Research Service/Wind Erosion Research Unit, 1992. $27 \mathrm{p}$.

WAGNER, L.E. \& YIMING, Y. Digitalization of profile meter photographs. Trans. Am. Soc. Agric. Eng., 43:412-416, 1991.

WISCHMEIER, W.H. \& SMITH, D.D. Rainfall energy and its relationship to soil loss. Trans. Am. Geophys. Union, 39:285-291, 1958.

WISCHMEIER, W.H. \& SMITH, D.D. Predicting rainfall erosion losses: A guide to conservation planning. Washington, United States Departament of Agriculture, 1978. 58p. (Agriculture Handbook, 537)

ZOLDAN JR. W.A. Rugosidade superficial do solo ocasionada por uma operação de escarificação aplicada após cinco anos e meio de uso de sistemas de manejo do solo, e suas relações com a erosividade da chuva e erosão hídrica em um Nitossolo Háplico. Lages, Universidade do Estado de Santa Catarina, 2006. 100p. (Tese de Mestrado)

ZOLDAN JR, W.A.; BERTOL, I.; PEGORARO, R.; FABIAN, E.L.; ZAVASCHI, E. \& VIDAL VÁZQUEZ, E. Rugosidade superficial do solo formada por escarificação e influenciada pela erosividade da chuva. R. Bras. Ci. Solo, 32:353-362, 2008. 